\title{
Pesquisa \& Psicanálise: Algumas Referências Lacanianas
}

\author{
Angela Cavalcanti Bernardes ${ }^{1}$ \\ Universidade Federal Fluminense
}

\begin{abstract}
RESUMO - Este estudo propõe uma discussão sobre alguns dos parâmetros que orientam a pesquisa no campo da psicanálise, levando-se em conta que esta não se reconhece nos critérios estatísticos e experimentais do discurso da ciência. Nesse sentido, são destacados dois aspectos específicos desse campo: o valor metodológico da singularidade do caso e a relação entre a formulação conceitual e o contexto enunciativo. Examina-se, ainda, duas referências de Jacques Lacan ao dito de Picasso: "Eu não procuro, eu acho". A perspectiva freudiana da indissociação entre pesquisa e prática é assimilada aqui à proximidade entre o trabalho investigativo e o trabalho do analisante na experiência analítica.
\end{abstract}

Palavras-chave: pesquisa em psicanálise; Lacan; singular; universal; conceito; suposição de saber.

\section{Research \& Psychoanalysis: Some Lacanian References}

\begin{abstract}
This paper suggests a discussion about some parameters that guide the research in the field of psychoanalysis, taking into account that such research is not based on the statistical and experimental criteria of the discourse of science. Two specific aspects of that field are pointed out: the methodological value of the case's singularity and the relation between the conceptual proposition and the enunciation context. It is also examined two Jacques Lacan's references to the Picasso's sentence: "I don't look for it, I find it". The Freudian indissociation perspective between research and practice is assimilated in relation to the proximity between the investigative work and the psychoanalyst work in the psychoanalytical experience.
\end{abstract}

Keywords: research in psychoanalysis; Lacan; singular; universal; concept; supposed to know.

\section{Do rigor da ciência}

... Naquele Império, a Arte da Cartografia alcançou tal Perfeição que o mapa de uma única Província ocupava toda uma Cidade, e o mapa do Império, toda uma Província. Com o tempo, esses Mapas Desmesurados não foram satisfatórios e os Colégios de Cartógrafos levantaram um Mapa do Império, que tinha o tamanho do Império e coincidia pontualmente com ele. Menos Afeitas ao Estudo da Cartografia, as Gerações Seguintes entenderam que esse dilatado Mapa era Inútil e não sem Impiedade o entregaram às Inclemencias do Sol e dos Invernos. Nos desertos do Oeste perduram despedaçadas Ruínas do Mapa, habitadas por Animais e por Mendigos; em todo o País não há outra relíquia das Disciplinas Geográficas. (Suárez Miranda: Viaje de Varones Prudentes, livro quarto, cap. XLV, Lérida, 1658)

$$
\text { Jorge Luis Borges }
$$

A discussão epistemológica aqui proposta não é a de interrogar 'o que é uma ciência que inclua a psicanálise', como formulou Lacan $(1964 / 1985 a)^{2}$, mas a de levantar alguns dos parâmetros que orientam uma pesquisa no campo da psicanálise, uma vez que os parâmetros científicos não lhe são apropriados.

1 Endereço para correspondência: Rua Professor Luis Cantanhede 214/201. Rio de Janeiro, RJ. CEP 22245-040. E-mail: angelabernardes@terra.com.br.

2 "Permanente donc restait la question qui fait notre projet radical: celle qui va de: la psychanalyse est-elle une science? à: qu'est-ce qu'une science qui inclut la psychanalyse?" (Lacan, 1973, quarta capa)
Partimos da constatação de que existe uma relação intrínseca entre investigação e tratamento no método freudiano. No texto redigido como verbete enciclopédico, Freud define psicanálise como um método de investigação dos processos psíquicos e um método terapêutico apoiado nessa investigação (Freud, 1922/1973). Ou seja, a investigação em uma análise é, ela própria, tratamento. Freud acrescenta, ainda, como acepção para o termo psicanálise, o conhecimento assim adquirido. A teoria psicanalítica entretém com a prática uma relação de interdependência: a teoria decorre da experiência e, inversamente, a concepção teórica determina o modo como se pratica. Vale lembrar o que disse Lacan no Seminário XI: os quatro conceitos fundamentais da psicanálise, referindo-se na ocasião ao conceito de transferência: "O conceito dirige o modo de tratar os pacientes. Inversamente, o modo de tratá-los comanda o conceito" (Lacan, 1964/1985a, p. 120).

De que forma essa indissociação entre investigação e prática se estende para a investigação psicanalítica fora de um tratamento? O que seria uma investigação "em psicanálise", fora da experiência analítica? Lacan forjou o termo "psicanálise em extensão" para se referir a "tudo o que resume a função de nossa Escola como presentificadora da psicanálise no mundo" (Lacan, 1967/2003, p. 251, grifo nosso) em oposição ao termo "psicanálise em intensão" no tratamento psicanalítico. Cabe ainda distinguir a psicanálise em extensão praticada na Escola de Psicanálise daquela da prática universitária, para nos perguntarmos o que seria a psicanálise em extensão na pesquisa universitária - assunto que nos detém aqui.

Sem afirmarmos uma especificidade da pesquisa em psicanálise na universidade, consideramos, no entanto, que a universidade pode acolher, de forma privilegiada, a pesquisa 
de psicanalistas. Essa tem sido nossa experiência e gostaríamos de tecer alguns comentários a partir dela.

Uma das formas de investigação no campo da psicanálise em extensão consiste na própria experiência de ensinar e supervisionar estágios. Constatamos que os seminários e supervisões obedecem à lógica que indissocia prática e construção de saber. Desde que algo da ordem do não-saber se aloje de forma operativa no âmago de nossa prática, por menos analítica que ela seja, essa prática implica uma investigação. Isso talvez seja um dos efeitos da análise de cada um no seu exercício na universidade.

Mas o que dizer da pesquisa stritu senso dos psicanalistas nas universidades? É sempre difícil definir as exigências de um trabalho de pesquisa em psicanálise porque esta não se orienta pelas exigências do discurso da ciência de reprodução experimental ou mensuração estatística. A esse respeito, vale lembrar que na década de 30 do século passado, Saul Rosenzweig realiza estudos experimentais para dar sustentação científica à psicanálise e recebe de Freud uma nota dizendo que a psicanálise se baseava em tantas observações fidedignas que não dependia de verificações experimentais (Monte \& Sollod, 2003/2006, p. 37). Ora, o papel da investigação em psicanálise na universidade não é o de transpor suas descobertas para o discurso da ciência. Pelo contrário, diríamos que tentativas nessa linha contrariam a orientação da psicanálise que tem outras prioridades e preocupações epistemológicas, obedecendo a outro ordenamento discursivo. No entanto, um rigor é exigível na elaboração acadêmica do psicanalista.

O desafio que se coloca para nós psicanalistas na universidade é o de conjugar o rigor acadêmico com o vigor psicanalítico. Por vigor entendemos o que se refere a uma pesquisa não somente sobre psicanálise, mas atravessada pela psicanálise, isto é, que compartilhe e atualize suas prioridades. Em primeiro lugar, que valorize e priorize as descobertas singulares. A extensão dessa premissa poderá ser avaliada pela análise epistemológica mencionada a seguir, que conclui: "A prova em psicanálise é sempre singular" (Regnault, 2003, p. 93).

\section{O Caso}

O pensador francês François Regnault retoma as principais objeções dos filósofos da ciência que recusam à psicanálise a prova científica para se perguntar: "Qual prova resta à psicanálise se a ciência recusa as suas?” (2003, p. 78). O autor desenvolve seu raciocínio em um extenso artigo do qual retemos essencialmente a distinção entre a teoria científica e a psicanálise, quanto à passagem do singular ao universal.

Um ponto em comum entre todas as epistemologias racionalistas, assinala Regnault (2003) é “a oposição entre formulações factuais singulares, a singularidade dos fatos, e as teorias universais, ou a universalidade da teoria" (p. 90). Ora, o que distingue a psicanálise dessas teorias, diz o autor, é precisamente que

a psicanálise passa da singularidade do caso à universalidade suposta da lei (ou da proposição teórica) sem a mínima mediação, à diferença das ciências cuja mediação é a própria reprodutibilidade da experiência ... o caso da análise não pode se repetir. (Regnault, 2003, p. 54)

O ‘caso’ em psicanálise não é algo como ‘um caso’ a ser agrupado numa categoria. $\mathrm{O}$ singular torna-se universal sem passar pelo particular, se empregarmos as categorias lógicas aristotélicas. Não tem o sentido de "é apenas um caso" (outros sendo necessários para formar uma classe), mas o de "é um caso!", no sentido de um fenômeno, uma exceção. A exclamação "é um caso!" designa a originalidade e ao mesmo tempo um protótipo. Regnault (2003) chega a propor que a palavra 'caso', em psicanálise, tem o sentido antitético das palavras primitivas estudado por Freud: "essa palavra [caso] designando tanto a regra quanto a exceção!" (p. 55). Ao empregarmos a expressão a histérica não é tanto para falar de um quadro clínico, em que todos os casos confirmam a regra, mas dessa histérica: da Dora, da minha paciente etc. Trata-se de um paradigma mais do que de uma classe. Se tomarmos a construção da cena primária no caso do "Homem dos lobos", temos um exemplo em que um caso singular conduz ao universal da articulação entre a cena traumática e a fantasia fundamental.

Nos dias de hoje, em que até mesmo a descrição dos quadros clínicos parece obsoleta frente ao critério estatístico da incidência dos fenômenos ${ }^{3}$, vale lembrar o valor metodológico do caso clínico em Psicanálise. A esse respeito, Suzana Barroso nos remete ao escrito "O mito individual do neurótico", no qual Lacan nos indica que "o valor metodológico de um caso clínico se encontra naquilo que ele tem de mais particular, e que é, justamente o que pode elevá-lo à condição de paradigma psicanalítico" (citado por Barroso, 2003, p. 23).

O valor da singularidade do caso é ressaltado por Freud ao indicar que cada caso deve ser escutado como se fosse o primeiro, colocando-se em reserva o saber sobre a teoria. Toda tentativa de classificação só pode ser feita a posteriori e, ainda assim, com o objetivo de melhor situar o analista na transferência - dimensão, aliás, ineliminável da "prova em psicanálise".

\section{Um Corte}

A indicação clínica de Freud acerca da singularidade do caso é também uma condição metodológica no sentido em que o saber sobre a clínica se elabora sempre no caso a caso e é sempre parcial. Por parcialidade entendemos a parte que cada qual toma na elaboração conceitual. Assim sendo, uma construção teórica em psicanálise inclui sempre a enunciação. Não há um ideal de neutralidade científica na apresentação dos resultados de uma pesquisa psicanalítica. Não se trata tampouco de uma apologia do achismo ou da proliferação do imaginário. Daí o interesse no trabalho com os pares, nas

3 Referimo-nos essencialmente ao papel preponderante, na atual prática médica, do Manual Diagnóstico e Estatístico editado pela American Psychiatric Association e adotado internacionalmente. 
discussões em grupo e no uso de um referencial semântico e conceitual compartilhado.

Os conceitos já estabelecidos são sempre examinados em seu contexto enunciativo. O pensamento de Freud, assim como o de Lacan, sempre sofreu reformulações e ao estudá-los sempre buscamos situá-los em seu contexto. De modo que o conceito em psicanálise vale não em termos de verdade positiva, mas, sobretudo, pela sua função instrumental.

Lacan, no Seminário I: Os escritos técnicos de Freud, compara a conceitualização em psicanálise à arte do bom cozinheiro que sabe cortar o animal bem na junta, soltando a articulação com a menor resistência. A nossa faca, o que nos permite fazer o corte preciso, é o nosso conceito. "Não é com a faca que dissecamos, mas com conceitos" (Lacan, 1953-54/1983, p. 10).

A conjugação de rigor com vigor, na qual insistimos, diz respeito ao manejo conceitual, mais especificamente, à eficácia do conceito. Guardando a metáfora do bom cozinheiro, é o caso de dizer que o nosso trabalho com os conceitos psicanalíticos deve cuidar para que eles não percam o fio. Ou seja, o risco da pesquisa universitária diz respeito à esterilização, à redução dos conceitos a palavras gastas. $\mathrm{O}$ saber sobre a psicanálise no discurso universitário tende a amortecer os efeitos de verdade do saber extraído da experiência psicanalítica.

Lançando mão da distinção lacaniana dos quatro discursos (Lacan, 1969-70/1991), é preciso observar que, no discurso universitário, o saber não apenas ocupa o lugar dominante, como, e sobretudo, é o discurso que visa a acumulação do saber. Ora, a experiência da psicanálise mostra que o saber não se acumula e não tende à totalização, de tal modo que a produção teórica nesse campo não visa preencher uma falha no saber. É verdade que, em várias ocasiões, Freud evoca o progresso da ciência que viria elucidar pontos obscuros que sua elaboração deixava em aberto. Mas, essencialmente, esse encaminhamento permitiu-lhe avançar deixando em aberto certos pontos que tocam no impossível de saber: a origem, o substrato da libido, a pulsão de morte. Freud indicou a solução científica no horizonte e avançou em outro terreno, com outros instrumentos: seus grandes constructos, dando forma ao obscuro. Assim sendo, ainda que respeitando as normas acadêmicas e atualizando-se em relação ao discurso dominante em seu tempo, a pesquisa em psicanálise na universidade se orienta por outro discurso que não o universitário.

\section{Circare}

Ao iniciar seu seminário sobre Os quatro conceitos fundamentais da psicanálise, endereçando-se ao auditório da École Normale Supérieure, constituído, entre outros, de grandes expoentes do pensamento francês na ocasião, Lacan indica sua reserva com relação ao termo pesquisa (recherche). O psicanalista diz nunca ter-se considerado um pesquisador (chercheur). Por oposição à démarche hermenêutica que busca (cherche) sempre outro sentido, Lacan cita Picasso: "Eu não procuro, acho" (Lacan, 1964/1985a, p. 14) (do francês "Je ne cherche pas, je trouve", Lacan, 1973, p. 12).

Em 1975, às voltas com as propriedades topológicas do nó borromeano, Lacan, aos olhos de certo observador de seus esforços tenazes, parecia se desmentir. Esse interlocutor teria lhe dito: "Pois aí eu o vejo procurar (chercher) pacas!", como relatado na aula de 13 de maio de 1975 do seminário R. S. I.. Nessa ocasião, então, Lacan se refere à etimologia do verbo chercher (procurar) que provém do latim circare: circundar, fazer o círculo. $\mathrm{O}$ círculo aqui diz respeito não à superfície plana de um disco, mas à forma vazada que cerca um buraco. O círculo sendo a consequência do buraco. É por ter encontrado um furo, um buraco, que ele tem que fazer o círculo: "Encontro o suficiente para ter que circular" (Lacan, 1974-75).

As duas passagens referidas acima (Lacan, 1964/1985a, 1974-75), com 11 anos de intervalo entre elas, podem nos servir para refletir sobre a relação entre a pesquisa e o encontro. Ao menos no campo da psicanálise, que é o nosso, somos de opinião que a pesquisa segue, a despeito do pesquisador, a mesma lógica do tratamento em relação a esse ponto: trata-se sempre do contorno, da circunscrição, de algo que se deu como um encontro num primeiro tempo para cada um.

Ao dizer isso, retomamos a imbricação entre pesquisa e tratamento, indicada inicialmente ao citarmos o verbete freudiano. É preciso, no entanto, observar que, na experiência analítica, é o analisante quem está em posição de investigação. Essa é a posição própria do analisante no trabalho analítico em busca de um saber sobre a sua verdade. A suposição de saber na base da transferência é inerente ao método freudiano da associação livre, isto é, à hipótese de que ao falar livremente ao analista, ideias inconscientes que dirigem o curso associativo serão colocadas à luz. No dispositivo freudiano, a suposição de um saber latente aos ditos é um componente essencial da transferência que se instaura ao implicar o analista nesse saber não-sabido (cf. Bernardes, 2003, pp. 123-25). Essa é a estrutura do "sujeito suposto saber" no pivô da transferência assinalada por Lacan (1964/1985a, 1967/2003). Muito embora a pesquisa do psicanalista, na universidade ou fora dela, não seja relativa ao saber inconsciente que o sujeito em análise supõe, a estrutura da suposição de saber está em marcha em qualquer pesquisa, o que coloca o pesquisador mais próximo da posição de analisante do que daquela de analista. É assim que interpretamos a afirmação de Lacan (1972-73/1985b, p. 9), segundo a qual ele estaria em posição de analisante ao proferir seu seminário. Pois, assim como observara aquele seu interlocutor, ao acompanharmos o percurso de Lacan em seu seminário, ao longo de quase um quarto de século, é possível constatar um trabalho de investigação em curso: a pesquisa tenaz de alguém que, por ter se deparado com o furo no saber, elabora os conceitos que permitam circunscrever o real da sua prática.

Dito isto, cabe ainda assinalar que o pesquisar como circare aponta para um inassimilável pelo saber no centro de qualquer saber que pode e deve ser acolhido num trabalho epistêmico que vise a transmissão da psicanálise. 


\section{Referências}

Barroso, S. F. (2003). Sobre o caso clínico: uma contribuição à metodologia em psicanálise. Almanaque de Psicanálise e Saúde Mental (IPSM-MG), 6, 19-23.

Bernardes, A. C. (2003). Tratar o impossivel: a função da fala em psicanálise. Rio de Janeiro: Garamond.

Freud, S. (1973). Psicoanalisis y teoria de la libido: dos artículos de Enciclopedia. Em Tognola, J. N (Org.), Obras completas de Sigmund Freud (pp. 2674-77). Madri: Biblioteca Nueva. (Trabalho original publicado em 1922)

Lacan, J. (1973). Le séminaire, livre XI: les quatre concepts fondamentaux en psychanalyse. Paris: Seuil.

Lacan, J. (1974-75). Seminário R. S. I. (inédito).

Lacan, J. (1983). O seminário, livro 1: os escritos técnicos de Freud (B. Milan, Trad.). Rio de Janeiro: Jorge Zahar. (Trabalho original publicado em 1953-54)

Lacan, J. (1985a). O seminário, livro 11: os quatro conceitos fundamentais da psicanálise (M. D. Magno, Trad.). Rio de Janeiro: Jorge Zahar. (Trabalho original publicado em 1964)
Lacan, J. (1985b). O seminário, livro 20: mais, ainda (M. D. Magno, Trad.). Rio de Janeiro: Jorge Zahar. (Trabalho original publicado em 1972-73)

Lacan, J. (1991). Le séminaire, livre XVII: L'envers de la psychanalyse. Paris: Seuil. (Trabalho original publicado em 196970)

Lacan, J. (2003). Outros escritos (V. Ribeiro, Trad.). Rio de Janeiro: Jorge Zahar. (Trabalho original publicado em 1967)

Monte, C., \& Sollod, R. (2006). Por trás da máscara; introdução às teorias da personalidade (S. Machado, Trad.). Rio de Janeiro: LTC. (Trabalho original publicado em 2003)

Regnault, F. (2003). La preuve em psychanalyse. La Cause Freudienne, 54, 54-95.
Recebido em 22.07.08

Primeira decisão editorial em 19.08.09

Versão final em 01.09.09

Aceito em 03.09.09 